\title{
Sex, Eye Size, and the Rate of Myopic Eye Growth Due to Form Deprivation in Outbred White Leghorn Chickens
}

\author{
Yen-Po Chen, ${ }^{1,2}$ Ankush Prashar, ${ }^{1}$ Paul M. Hocking, ${ }^{3}$ Jonathan T. Erichsen, ${ }^{1}$ Chi Ho To, ${ }^{4}$ \\ Frank Schaeffel, ${ }^{5}$ and Jeremy A. Guggenheim ${ }^{1}$
}

Purpose. There is considerable variation in the degree of formdeprivation myopia (FDM) induced in chickens by a uniform treatment regimen. Sex and pretreatment eye size have been found to be predictive of the rate of FD-induced eye growth. Therefore, this study was undertaken to test whether the greater rate of myopic eye growth in males is a consequence of their larger eyes or of some other aspect of their sex.

Methods. Monocular FDM was induced in 4-day-old White Leghorn chicks for 4 days. Changes in ocular component dimensions and refractive error were assessed by A-scan ultrasonography and retinoscopy, respectively. Sex identification of chicks was performed by DNA test. Relationships between traits were assessed by multiple regression.

Results. FD produced (mean \pm SD) $13.47 \pm 3.12 \mathrm{D}$ of myopia and $0.47 \pm 0.14 \mathrm{~mm}$ of vitreous chamber elongation. The level of induced myopia was not significantly different between the sexes, but the males had larger eyes initially and showed greater myopic eye growth than did the females. In multiple linear regression analysis, the partial correlation between sex and the degree of induced eye growth remained significant $(P=0.008)$ after adjustment for eye size, whereas the partial correlation between initial eye size and the degree of induced eye growth was no longer significant after adjustment for sex $(P=0.11)$. After adjustment for other factors, the chicks' sex accounted for $6.4 \%$ of the variation in FD-induced vitreous chamber elongation.

Conclusions. The sex of the chick influences the rate of experimentally induced myopic eye growth, independent of its effects on eye size. (Invest Ophthalmol Vis Sci. 2010;51: 651-657) DOI:10.1167/iovs.09-3826

From the ${ }^{1}$ School of Optometry and Vision Sciences, Cardiff University, Cardiff, Wales, United Kingdom; the ${ }^{2}$ Department of Ophthalmology, Chang Gung Memorial Hospital, Taoyuan, Taiwan; the ${ }^{3}$ Department of Genetics and Genomics, Roslin Institute and Royal (Dick) School of Veterinary Studies, University of Edinburgh, United Kingdom; the ${ }^{4}$ Center for Myopia Research, School of Optometry, Hong Kong Polytechnic University, Hong Kong; and the ${ }^{5}$ Ophthalmic Research Institute, Section of Neurobiology of the Eye, Tübingen, Germany.

Supported by European Union Framework 6 Research Training Network Grant MRTN-CT-2006-034021 MYEUROPIA.

Submitted for publication April 7, 2009; revised June 23 and August 12, 2009; accepted August 19, 2009.

Disclosure: Y.-P. Chen, None; A. Prashar, None; P.M. Hocking, None; J.T. Erichsen, None; C.H. To, None; F. Schaeffel, None; J.A. Guggenheim, None

Corresponding author: Jeremy A. Guggenheim, School of Optometry and Vision Sciences, Cardiff University, Maindy Road, Cardiff CF24 4LU, Wales, UK; guggenheim@cf.ac.uk.
$\mathrm{M}$ yopia affects approximately $20 \%$ to $25 \%$ of individuals in most Western populations, with a much higher prevalence $(>50 \%)$ in certain Asian populations. ${ }^{1-3}$ Both genetic and environmental factors are implicated in the etiology of myopia. The higher within-pair correlations for refractive error found in monozygotic twins compared with dizygotic twins are consistent with an important genetic component of myopia ${ }^{4-7}$ and parental history of myopia has been shown in some,, 89 but not all, ${ }^{10-12}$ studies to exert an influence on children's eye size before the onset of myopia. However, as reviewed by Morgan and Rose, ${ }^{13}$ some researchers have argued that the interpretation of studies of twins with myopia is not straightforward, because exposure to environmental risk factors can be different in monozygotic and dizygotic twin pairs, thus violating the so-called common-environment assumption. Thus, a less controversial body of evidence for a genetic contribution to refractive error comes from the identification of several genes and genetic loci for refractive error. ${ }^{14,15}$ As well as including loci from studies of familial high myopia, several genome-wide significant loci have been found by examining ocular refraction as a quantitative trait, covering the full spectrum from myopia to hyperopia ${ }^{16-18}$ In those cases in which the gene concerned has been identified and replicated (e.g., the HGF and COL $2 A 1$ genes), ${ }^{19-22}$ it seems unlikely that the genetic risk is manifested by a change in behavior that increases exposure to an environmental risk factor, thereby ruling out an indirect environmental effect (but this situation could hold for some of the myopia susceptibility genes that have yet to be characterized). Recent epidemiologic studies of environmental risk factors such as time spent engaged in outdoor activity and urban versus rural dwelling, have shown these variables to be strongly associated with myopia development. ${ }^{23-26}$ However, as with the genetic studies, such epidemiology findings have not been universal: For example, a study of school children from a rural part of China found that time spent in outdoor activities was not associated with myopia. ${ }^{27}$ In the same study of Chinese school children, ${ }^{27}$ the intensively studied risk factor of time spent doing near work also was not associated with myopia, highlighting the difficulty researchers have faced in trying to understand the relationship between these variables. ${ }^{28}$ Thus, although the precise mechanisms of myopia's development are still unclear, a range of genetic and environmental influences seems likely. ${ }^{29}$

Studies in animal models demonstrate conclusively that perturbations in early visual experience can disrupt emmetropization to produce refractive errors in a wide range of species, including the chicken, ${ }^{30}$ tree shrew, ${ }^{31}$ macaque, ${ }^{32}$ marmoset, ${ }^{33}$ mouse, ${ }^{34}$ and guinea pig. ${ }^{35}$ The myopia induced in animal models shares characteristic features with the naturally occurring myopia of humans-for example, an increase in the axial length of the eye due principally to elongation of the vitreous chamber. ${ }^{36,37}$ 
There is often considerable interanimal variability in the degree of myopia induced by a uniform regimen of form deprivation (FD). ${ }^{38-40}$ In chickens, this differential susceptibility to myopia occurs not only between strains, but also within strains. ${ }^{38,39}$ Little is known about what causes this effect. Zhu et al. $^{41}$ found that sex influenced susceptibility to FDM in White Leghorn chicks, yet Schmid and Wildsoet ${ }^{39}$ found that it did not. Studies in fish also suggest that body size (specifically, body weight) influences susceptibility to FDM. ${ }^{40}$ The hypothesis that the differential sensitivity to FDM has a genetic origin has been discussed by several authors. ${ }^{38,42}$ Perhaps the most convincing evidence in favor of this hypothesis is the significant correlation in the magnitude of the response of chickens to two sequential periods of FD with a recovery interval between. $^{43}$

The completion of a relatively large study of FDM in an outbred population of White Leghorn chickens provided us with the opportunity to explore the role of the chick's sex in determining susceptibility to FDM in detail. In particular, we were interested to test whether sex exerts its effects on susceptibility to myopic eye growth by virtue of the eye size differences between the sexes, ${ }^{41,44}$ and/or by an independent effect (Fig. 1).

\section{Materials AND Methods}

\section{Animals}

Lohmann strain White Leghorn chicks (Gallus gallus domesticus) were obtained from Lohmann Tierzucht (Cuxhaven, Germany) as fertilized eggs. This strain has been maintained by random mating of a very large population group undergoing selection for production traits by the breeding company and was expected to exhibit a high level of genetic diversity for eye traits

Before FDM induction, the chicks were raised in a temperaturecontrolled brooder with transparent Plexiglas sides and lid. During the period of FD, the chicks were kept in a large transparent Plexiglas/ wire-mesh floor pen, heated by an overhead infrared lamp. Food and water were provided ad libitum. Fluorescent lamps mounted on the ceiling of the room provided an illumination of approximately 280 lux at chick eye level in the brooder and 250 lux in the floor pen (with a 12:12-hour light/dark cycle).

The sex of the chicks was determined by a PCR/restriction enzyme digest assay with DNA extracted from a blood sample, ${ }^{45-47}$ or by examination of secondary sexual characteristics in adult birds, or by both methods. All aspects of the care and use of the chicks conformed to the U.K. legislation and the European Communities Council Directive 86/609/EEC (1986) and complied with the ARVO Statement for the Use of Animals in Ophthalmic and Vision Research.

\section{Form Deprivation}

Monocular deprivation of form vision was performed for 4 days, beginning when the chicks were 4 days old. Wallman and Adams ${ }^{48}$ found that ocular changes to visual deprivation in chicks were evident after treatment for only 3 days. A pilot experiment in outbred Lohmann White Leghorn chicks suggested that interanimal variability in response to FD was clearly evident after 4 days, while at the same time ensuring that the FDM response had not yet reached its plateau. Ocular component dimensions were measured before and after the period of FD. Ocular refraction was measured only after FD.

Translucent diffusers were made from a sheet of 0.8 -mm-thick polypropylene with an absorbance of $0.07 \mathrm{log}$ units. The polypropylene sheet was heated and compression molded into appropriately sized hemispheres. All diffusers were checked by eye for flaws in an attempt to ensure uniformity of shape and translucency. To induce myopia, we sutured a diffuser to the skin around the orbit of the left eye with monofilament nonabsorbable suture material (Ethilone 4-0; Ethicon, Johnson \& Johnson Intl., Norderstedt, Germany) while the animal was under general anesthesia (produced by an intramuscular injection of ketamine $50 \mathrm{mg} / \mathrm{kg}$ and xylazine $3.5 \mathrm{mg} / \mathrm{kg}$ ). After recovery from anesthesia, we made certain that the chicks could open the occluded eye freely. Diffusers were removed after 4 days of FD by removal of the sutures. The right eyes of chicks were untreated and served as a paired control.

\section{Ocular Measurements and Quantification of Myopia Susceptibility}

Ocular component dimensions-anterior chamber depth (ACD), lens thickness (LT), vitreous chamber depth (VCD), and axial length (AL)were measured with high-frequency A-scan ultrasonography. ${ }^{44}$ Measurements were obtained before and after the period of FD, while the chicks were anesthetized. The refractive (RF) state of each eye was measured in the dark using noncycloplegic streak retinoscopy, on awake chicks, immediately after removal of the diffuser. (Note that RF was not measured before $\mathrm{FD}$, since in preliminary tests the difference in refraction between fellow eyes was of the same order of magnitude as the measurement error of repeat noncycloplegic streak retinoscopy assessments; and, in our hands, photorefraction was no more precise than retinoscopy). We were unable to measure RF on chicks while they were anesthetized (and thus cyclopleged), because this necessitated the use of a speculum or some other method of opening the lids, which induced astigmatism. Keratometry was not measured in this experiment, since, in outbred chickens at least, changes in corneal curvature represent a minor structural correlate of FDM compared with changes in VCD. ${ }^{38,47}$ Body weight was measured (to the nearest gram) before, and after, the period of FD.

Susceptibility to FDM was quantified using three variables, $\triangle V C D$, $\triangle A L$, and $\triangle R F$, defined as:

$$
\begin{gathered}
\Delta V C D=\Delta V C D_{\mathrm{T}}-\Delta V C D_{\mathrm{C}} \\
\Delta A L=\Delta A L_{\mathrm{T}}-\Delta A L_{\mathrm{C}} \\
\Delta R F=R F_{\mathrm{C}}-R F_{\mathrm{T}}
\end{gathered}
$$

where, $\triangle V C D_{\mathrm{T}}$ is VCD in the treated eye after FD minus VCD in the treated eye before FD; $\triangle V C D_{\mathrm{C}}$ is $\mathrm{VCD}$ in the control eye after FD minus $\mathrm{VCD}$ in the control eye before $\mathrm{FD} ; \Delta A L_{\mathrm{T}}$ is $\mathrm{AL}$ in the treated eye after FD minus $\mathrm{AL}$ in the treated eye before $\mathrm{FD} ; \triangle A L_{\mathrm{C}}$ is $\mathrm{AL}$ in the control eye after FD minus $\mathrm{AL}$ in the control eye before $\mathrm{FD} ; R F_{\mathrm{T}}$ is $\mathrm{RF}$ in the treated eye after $\mathrm{FD}$; and $R F_{\mathrm{C}}$ is $\mathrm{RF}$ in the control eye after FD.

\section{Statistical Analysis}

The frequency distributions of $\triangle V C D, \triangle A L$, and $\triangle R F$ and the ocular component dimensions were tested for normality by using the Kolmogorov-Smirnov test. Because the data for $\Delta R F$ were nonnormally distributed, the Spearman correlation coefficient was used to test the relationships $\triangle R F$ versus $\triangle V C D$ and $\triangle R F$ versus $\triangle A L$. Comparisons between the ocular component dimensions before and after FD were made by using paired $t$-tests, and Pearson's correlation coefficient was used to investigate the relationship between susceptibility to FD and sex or initial ocular component dimensions (ocular component dimensions before FD). A general linear model (GLM) was used to adjust measures of susceptibility to FD for the effect of hatch-to-hatch variability (a "batch effect"). Multiple linear regression analysis was performed to investigate the association between myopia susceptibility, sex, and body weight. To decide between the potential causal models explaining the relationship between sex, initial eye size, and myopia susceptibility (Fig. 1), we examined the partial correlation coefficients from the regression analysis (SPSS version 12.0, SPSS Inc., Chicago, IL).

\section{Results}

\section{Sex and Eye Size}

Because of limited capacity in our animal facility, the experiment was performed in 15 separate hatchings (batches) of 
TABLE 1. Ocular Component Dimensions before and after FD

\begin{tabular}{lccc}
\hline $\begin{array}{l}\text { Ocular Component } \\
\text { Dimensions }(\mathbf{m m})\end{array}$ & $\begin{array}{c}\text { Male } \\
(\boldsymbol{n}=\mathbf{1 1 7})\end{array}$ & $\begin{array}{c}\text { Female } \\
(\boldsymbol{n}=\mathbf{1 1 5})\end{array}$ & $\boldsymbol{P}^{*}$ \\
\hline $\begin{array}{l}\text { Both eyes prior to FD } \\
\text { ACD }\end{array}$ & $1.27 \pm 0.04$ & $1.25 \pm 0.04$ & $<0.001$ \\
LT & $1.83 \pm 0.04$ & $1.81 \pm 0.03$ & $<0.001$ \\
VCD & $5.09 \pm 0.12$ & $4.99 \pm 0.13$ & $<0.001$ \\
AL & $8.19 \pm 0.14$ & $8.05 \pm 0.15$ & $<0.001$ \\
Treated eye after FD & $1.38 \pm 0.10$ & $1.33 \pm 0.08$ & $<0.001$ \\
ACD & $1.97 \pm 0.04$ & $1.96 \pm 0.06$ & 0.07 \\
LT & $5.62 \pm 0.17$ & $5.43 \pm 0.19$ & $<0.001$ \\
VCD & $8.96 \pm 0.25$ & $8.71 \pm 0.23$ & $<0.001$ \\
AL & $1.40 \pm 0.04$ & $1.36 \pm 0.04$ & $<0.001$ \\
Control eye after FD & $1.97 \pm 0.04$ & $1.96 \pm 0.06$ & 0.11 \\
ACD & $5.15 \pm 0.13$ & $5.03 \pm 0.13$ & $<0.001$ \\
LT & $8.52 \pm 0.15$ & $8.33 \pm 0.16$ & $<0.001$ \\
VCD & & & \\
AL & & & \\
\hline
\end{tabular}

Data are expressed as the mean $\pm \mathrm{SD}$.

${ }^{*} t$-test for a difference between sexes.

chicks. The number of chicks in each batch varied from 10 to 25 (mean, 15). In total, 232 chicks were studied, comprising 117 males and 115 females. The sexes were identified by DNA analysis in 175 chicks, by observation of secondary sexual characteristics, such as larger comb and stature in the males and egg-laying in the females, in 32 chicks that were allowed to mature; and by both methods in 25 chicks. For the latter group of 25 chicks, the results of sex identification were fully concordant. Before FD treatment, all ocular component dimensions were significantly larger in the male chicks than in the females (all $P<0.001$; Table 1).

\section{Variation in Susceptibility to FD}

The changes in ocular component dimensions induced by FD are summarized in Tables 1 and 2. After 4 days of FD, there were significant differences in ACD, VCD, and AL between treated and control eyes (paired $t$-test, all $P<0.001$ ), but this was not the case with LT $(P=0.39)$. Relative to control eyes, treated eyes showed large increases in VCD and AL and a small decrease in ACD. Thus, the axial elongation induced by FD was mainly the result of an increase in VCD.

Myopia susceptibility was quantified as the difference in growth between treated and control eyes during FD (parameters $\triangle V C D$ and $\triangle A L)$ and as the difference in refraction between treated and control eyes after FD (parameter $\Delta R F$ ). There was substantial variability in myopia susceptibility in this outbred Lohmann strain of chicks (Table 2). The coefficients of variation were: $\triangle V C D, 30 \% ; \Delta A L, 42 \% ; \Delta R F, 23 \%$. Both $\Delta V C D$ and $\Delta A L$ were highly correlated with $\Delta R F(r=0.55$ and $r=$ 0.68 , respectively; both $P<0.001)$.

After FD, the male chicks (still) had significantly longer eyes than did the female chicks. Specifically, both the treated and control eyes of the male chicks had deeper anterior and vitreous chambers, and longer overall ALs than did the corresponding eyes of the females (all $P<0.001$; Table 1 ). By contrast, lens thickness was no longer significantly greater in the males than in the females after FD in either the treated or control eye (Table 1). In terms of the relative changes in ocular component dimensions, only the relative change in VCD and AL (i.e., $\triangle V C D$ and $\triangle A L$ ) were significantly different between the sexes, with males again showing a greater relative increase in ocular component dimensions than females (Table 2). In summary, the male chicks had larger eyes before FD, larger eyes after FD, and developed a greater degree of FD-induced myopic eye growth than the females. An important finding, however, is that the males did not develop more FD myopia per se than did the females (Table 2).

\section{Eye Size, Sex, and the Rate of Experimentally Induced Eye Growth}

Eye size before FD was found to be a predictor of susceptibility to the treatment's growth-inducing effects. Specifically, there were significant correlations between initial ACD and $\triangle V C D$ $(r=0.23, P<0.001)$, initial VCD and $\triangle V C D(r=0.16, P=$ $0.014)$, and initial AL and $\triangle V C D(r=0.20, P=0.003)$. However, initial LT did not correlate significantly with $\triangle V C D(r=$ $-0.01, P=0.895)$. Similar to these associations with $\triangle V C D$, there was significant correlation between the initial $\mathrm{AL}$ and $\Delta A L(r=0.15, P=0.020)$.

As mentioned, the chick's sex also predicted its susceptibility to experimentally induced eye growth. The correlation between the sex and $\triangle V C D$ was $r=0.24, P<0.001$. Thus, in univariate analyses, both the sex and the initial eye size were significant predictors of susceptibility to $\triangle V C D$ (accounting for $6.4 \%$ and $3.8 \%$ of the variance in response, respectively). Because the directions of the potential causal relationships between the chick's sex, initial eye size, and susceptibility to myopia were unambiguous (e.g., it would not be logical for either myopia susceptibility or eye size to determine sex), we proposed three potential causal effect models to explain the interrelationships among sex, eye size, and the susceptibility to myopic eye enlargement (Fig. 1).

According to model 1, the chick's sex exerted its effects on the rate of eye enlargement solely by virtue of its having produced a difference in initial eye size between the sexes. In model 2, sex influenced susceptibility independent of its effects on initial eye size, and in model 3, sex influenced susceptibility both directly (independent of eye size) and indirectly, as a result of producing differences in initial eye size. When both sex and initial eye size (and body weight) were included in a multiple regression model, sex was the only significant predictor of the rate of eye enlargement (Table 3). As outlined in the following text, this result suggested that causal effects model 2 was most consistent with our observations.

If model 1 were correct, then controlling for eye size should remove the correlation between the chick's sex and the rate of

TABLE 2. Myopia Susceptibility

\begin{tabular}{lcccc}
\hline Parameter & $\begin{array}{c}\text { All } \\
(\boldsymbol{n}=\mathbf{2 3 2})\end{array}$ & $\begin{array}{c}\text { Male } \\
(\boldsymbol{n}=\mathbf{1 1 7})\end{array}$ & $\begin{array}{c}\text { Female } \\
(\boldsymbol{n}=\mathbf{1 1 5})\end{array}$ & $\boldsymbol{P}$ \\
\hline$\Delta V C D(\mathrm{~mm})$ & $0.47 \pm 0.14$ & $0.50 \pm 0.13$ & $0.44 \pm 0.14$ & $<0.001^{*}$ \\
$\Delta A L(\mathrm{~mm})$ & $0.45 \pm 0.19$ & $0.49 \pm 0.19$ & $0.41 \pm 0.17$ & $0.002^{*}$ \\
$\Delta R F(\mathrm{D})$ & $13.47 \pm 3.12$ & $13.60 \pm 3.30$ & $13.33 \pm 2.93$ & $0.573 \dagger$ \\
\hline
\end{tabular}

Data are expressed as the mean $\pm \mathrm{SD}$ and reflect the differences between treated and control eyes after 4 days of FD.

* $t$-Test for a difference between sexes.

† Mann-Whitney test. 


\section{Model 1}

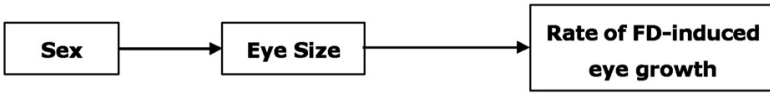

Model 2

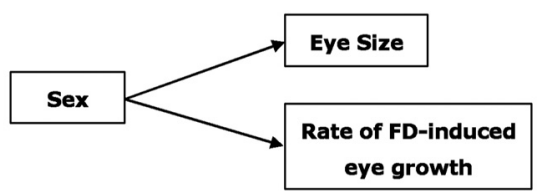

Model 3

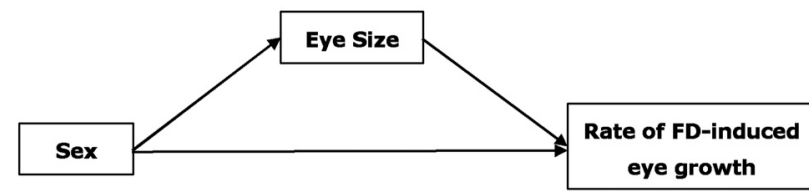

Figure 1. Potential models describing the relationships between sex, eye size before FD, and the rate of FD-induced eye growth. Arrows: direction of causal effects.

myopic eye growth. However, this was not the case. The partial correlation between sex and $\triangle V C D$ with initial AL held constant and was still significant $(r=0.175, P=0.008)$, demonstrating that model 1 was incorrect. If model 3 were correct, then controlling for sex should not remove the correlation between initial eye size and susceptibility to FD, because an independent causal link between these latter two variables should remain. However, there was no longer a significant partial correlation between initial $\mathrm{AL}$ and $\triangle V C D$, with sex held constant $(r=0.11, P=0.11)$, suggesting that model 3 was also incorrect. Thus, the model that was most consistent with the observed data was model 2 -that is, the model in which sex exerted its influence on eye size and the rate of myopic eye growth independently. (We note, however, that the result obtained when controlling for sex could have been strongly influenced by a lack of power due to our modest sample size. Hence, we could not rule out model 3 with the confidence with which we could exclude model 1$)$. The proportion of the variance in $\triangle V C D$ predicted by sex was $6.4 \%(P<0.001$; Table $3)$. Body weight was not a significant predictor of the degree of induced myopia $(P=0.99)$ or of the rate of myopic eye growth (Table 3 ) in multiple regression models.

\section{Discussion}

The outbred chicks that we studied showed a varied response to $\mathrm{FD}$, as has been noted many times in other White Leghorn and non-White Leghorn lines. ${ }^{38,39,47-49}$ An important result of our study was that the level of induced myopia was not significantly different between the male and female chicks. Rather, the eyes of the male chicks elongated to a greater degree in response to FD than did the eyes of the female chicks (which implies that the anterior segments of the sexes must also have been different). Our finding that approximately $6 \%$ of the intersubject variability in FD-induced eye growth could be predicted by knowing the sex of the animal is consistent with the hypothesis that the differential susceptibility to FD is partially genetic in origin. ${ }^{38,42,43}$ Initial eye size (i.e., AL before FD) was also a statistically significant predictor of the rate of myopic eye growth. However, multiple regression analysis suggested that this relationship was possibly one of "guilt by association"-that is, it represented a noncausal relationship produced by virtue of the tendency for the male chicks to have larger eyes than the female chicks before FD.

Schmid and Wildsoet ${ }^{39}$ found similar responses to FD in male and female White Leghorn and broiler crossbred chicks. However, Zhu et al. ${ }^{41}$ identified a higher susceptibility to FDM in male White Leghorn chicks. These conflicting results may be due to the different genetic backgrounds of the chicken lines concerned, or chance effects due to sampling variation (in view of the limited extent of sex's influence on myopia susceptibility). The fact that we found the chicks' sex to exert an effect on eye size and FD-induced eye growth independently suggests that the genes responsible for the increased eye size in males are not necessarily the same genes that give rise to the enhanced rate of myopic eye growth in males. In contrast to the findings of Shen et al. ${ }^{50}$ that susceptibility to FDM in fish is strongly related to initial body weight, there was no such relationship in the chicks that we studied (Table 3).

There is an extensive body of statistical literature on the difficulty of attributing specific anatomic differences in scale to the sex of the subject. ${ }^{51}$ Usually, the problem is one of deciding whether a given morphologic region of interest (ROI) is larger in males simply by virtue of males being larger than females in general, or because of a specific enlargement of the ROI in males over and above the general size difference between the sexes. Thus, the question is one of relative scaling (for example, the size of the ROI relative to overall body size). Although the question we wanted to address was not precisely the same as this, it shared the same inherent property: Namely, one could phrase our research question as, "Is the greater myopic eye growth of male chicks due to their larger initial eye

TABLE 3. Multiple Regression Analysis Identifying Predictive Variables Associated with the Rate of Myopic Eye Growth

\begin{tabular}{|c|c|c|c|c|c|c|}
\hline \multirow[b]{2}{*}{ Model } & \multirow[b]{2}{*}{ Adjusted $R^{2}$} & \multirow[b]{2}{*}{ Predictors } & \multirow[b]{2}{*}{$\mathbf{B}^{*}$} & \multirow[b]{2}{*}{$\boldsymbol{P}$} & \multicolumn{2}{|c|}{ Correlations } \\
\hline & & & & & Zero-Order & Partial \\
\hline \multirow[t]{3}{*}{ A } & 0.068 & Sex & 0.204 & 0.004 & 0.260 & 0.187 \\
\hline & & Eye size & 0.141 & 0.078 & 0.206 & 0.116 \\
\hline & & Body weight & -0.050 & 0.492 & 0.036 & -0.045 \\
\hline \multirow[t]{2}{*}{$\mathrm{B}$} & 0.070 & Sex & 0.210 & 0.003 & 0.260 & 0.193 \\
\hline & & Eye size & 0.115 & 0.102 & 0.206 & 0.108 \\
\hline $\mathrm{C}$ & 0.064 & Sex & 0.260 & $<0.001$ & 0.260 & - \\
\hline
\end{tabular}

$\triangle V C D$ resulting from 4 days of FD was examined as a function of sex, initial eye size (i.e. axial length prior to treatment), and initial bodyweight. All variables were included in the starting model 1 , followed by backward removal of variables to identify the more parsimonious models 2 and 3 .

* Standardized regression coefficient. 
Table 4. A Selection of Previous Studies in Which a Difference between the Sexes in the Prevalence of Myopia in Human Subjects Was Reported

\begin{tabular}{|c|c|c|c|c|c|c|}
\hline Study & $\begin{array}{l}\text { Subject } \\
\text { Ethnicity }\end{array}$ & $\begin{array}{l}\text { Definition of } \\
\text { Myopia }\end{array}$ & Sample Size $(M / F)$ & $\begin{array}{l}\text { Subject Age } \\
\text { Range (y) }\end{array}$ & $\begin{array}{c}\text { Myopia Prevalence } \\
(\%)(\mathrm{M} / \mathrm{F})\end{array}$ & Study Type \\
\hline Goldschmidt ${ }^{63}$ & Caucasian & $<-1.50 \mathrm{D}$ & $9,243(4,605 / 4,638)$ & $13-14$ & $\begin{array}{l}\text { Total: } 5.1 / 6.7 \\
\quad \text { Academic: } 7.3 / 9.4\end{array}$ & Cohort \\
\hline $\begin{array}{l}\text { Matsumura } \\
\text { and Hirai }\end{array}$ & Asian & $\begin{array}{l}\text { Mean spherical } \\
\text { power }<-0.50 \mathrm{D}\end{array}$ & 346 & $3-17$ & $\begin{array}{l}\text { Boys: } 40.4 \rightarrow 66.0 \\
\text { Girls: } 46.3 \rightarrow 66.7 \\
\text { Higher progression } \\
\text { rate in boys } \\
(P<0.0001)\end{array}$ & Cohort \\
\hline Lin et al. ${ }^{64}$ & Asian & $\begin{array}{c}\mathrm{SE}<-0.25 \mathrm{D} \\
\text { cycloplegia }+\end{array}$ & $11,178(5,676 / 5,502)$ & $7-18$ & $50 / 58$ & Cross-sectional \\
\hline Wong et al. ${ }^{65}$ & Asian & $\begin{array}{l}\mathrm{SE}<-0.50 \mathrm{D} ; \text { high } \\
\text { myopia: } \\
\mathrm{SE}<-5.00 \mathrm{D}) \\
\text { no cycloplegia }\end{array}$ & $1,113(500 / 613)$ & $40-79$ & $\begin{array}{l}\text { Myopia: } 33.0 / 36.5 \\
\text { High Myopia: } \\
5.2 / 8.3\end{array}$ & Cross-sectional \\
\hline Zhao et al. ${ }^{66}$ & Asian & $\begin{array}{l}\mathrm{SE}<-0.50 \mathrm{D} \\
\text { cycloplegia }+\end{array}$ & $4,621(2,384 / 2,237)$ & $5-13$ & $\begin{array}{l}\text { Myopic shift }>0.50 \\
D \text { in females } \\
(\mathrm{OR}=1.89)\end{array}$ & Cohort \\
\hline He et al. ${ }^{67}$ & Asian & $\begin{array}{c}\mathrm{SE}<-0.50 \mathrm{D} \\
\text { cycloplegia }+\end{array}$ & $2,400(1,222 / 1,178)$ & $13-17$ & $\begin{array}{l}\text { Higher prevalence } \\
\text { in females } \\
(\mathrm{OR}=2.15)\end{array}$ & Cross-sectional \\
\hline $\mathrm{Xu}$ et al. ${ }^{68}$ & Asian & $\begin{array}{l}\mathrm{SE}<-0.50 \mathrm{D} \\
\text { no cycloplegia }\end{array}$ & $4,319(2,424 / 1,895)$ & $40-90$ & $\begin{array}{l}\text { Higher prevalence } \\
\text { in females } \\
\quad(P<0.001)\end{array}$ & Cohort \\
\hline Saw et al. ${ }^{53}$ & Asian & $\begin{array}{l}\mathrm{SE}<-0.50 \mathrm{D} \\
\text { no cycloplegia }\end{array}$ & $2,974(1,427 / 1,547)$ & $40-79$ & $\begin{array}{l}22.2 / 26.8(\mathrm{OR}= \\
1.87, P=0.015)\end{array}$ & Cross-sectional \\
\hline Vitale et al. ${ }^{69}$ & Mixed & $\begin{array}{l}\mathrm{SE}<-1.00 \mathrm{D} ; \\
\text { no cycloplegia }\end{array}$ & $12,010(5,790 / 6,220)$ & $>20$ & $\begin{array}{l}32.6 / 39.9(P< \\
0.001)\end{array}$ & Cross-sectional \\
\hline
\end{tabular}

SE, spherical equivalent; OR, odds ratio.

size, or is it due to an effect of sex over and above this?" The way in which the relative size of an ROI is defined can profoundly influence the results obtained when testing for an effect of sex. Because of this, we tested two alternative methods of defining the degree of myopic eye growth, in addition to those we termed $\triangle V C D$ and $\triangle A L$ (Supplementary Table S1, http://www.iovs.org/cgi/content/full/51/2/651/DC1). In each case, the findings were the same, providing a measure of confidence that our conclusion was not dependent on any one set of definitions.

In humans, differences in myopia prevalence between the sexes are frequently although not always found (Table 4). For instance, Matsumura and Hirai ${ }^{52}$ reported a significant gender difference in the change in refractive error during a 6-year follow-up of mass ophthalmic surveys of Japanese students, and Saw et al. ${ }^{53}$ recently revealed that being of female sex was significantly associated with myopia $(O R=1.87)$ in the Singapore Malay population. Moreover, two genetic loci for high myopia have been mapped to the $\mathrm{X}$ chromosome to date: MYP1 atXq28 $8^{54}$ and MYP13 at Xq23-25, 55,56 as has a genetic locus for "low" (common) myopia. ${ }^{57}$ However, the genetics of sex determination in mammals and birds is very different. Whereas it is males who are the heterogametic sex in mammals (males carry $\mathrm{X}$ and $\mathrm{Y}$ chromosomes, females two $\mathrm{X}$ chromosomes) in birds it is females who are heterogametic (males ZZ, females $\mathrm{ZW}$ ). Thus, while gene dosage appears to be important in sex determination in both mammals and birds, ${ }^{58}$ there is little or no synteny between the human $X$ chromosome and the chicken $\mathrm{Z}$ chromosome (specifically, the chicken $\mathrm{Z}$ chromosome is syntenic with regions of human chromosomes 5, 8, 9, and 18). ${ }^{59-62}$ Since the degree of induced myopia in the chickens that we studied was not significantly different between the sexes, our results are not consistent with prior findings of sex-related differences in the prevalence of human myopia. Furthermore, since the chicken $\mathrm{Z}$ and human $\mathrm{X}$ chromosomes are not syntenic, our findings do not implicate genes on the $\mathrm{X}$ chromosome as being especially likely to modulate axial eye growth differently in males and females. (Instead, human chromosomes 5, 8, 9, and 18 may be interesting to study in regard to possible sex differences in humans.)

In conclusion, we found the sex of White Leghorn chicks to influence the rate of FD-induced myopic eye growth, with the males having a greater degree of axial elongation than the females. A chicken's initial eye size and its body weight were not predictive of susceptibility to FDM or the rate of myopic eye growth, once the effect of its sex was taken into account. The mechanism through which the chick's sex affects the rate of myopic eye growth is unknown, but since (1) sex-related dimorphism of body size in chickens is striking and (2) approximately $50 \%$ of the variation in normal eye size in chickens appears to be related to generalized body size variation, ${ }^{44}$ one appealing hypothesis is that levels of sex hormones interact with other growth-promoting stimuli to influence the rate of myopic eye growth. Alternatively, a difference in dosage for one or more genes on the chicken $\mathrm{Z}$ chromosome could underlie the phenomenon.

\section{Acknowledgments}

The authors thank Lohmann Tierzucht GmbH (Cuxhaven, Germany) for kindly donating fertile eggs for the study.

\section{References}

1. Saw SM. A synopsis of the prevalence rates and environmental risk factors for myopia. Clin Exp Optom. 2003;86:289-294.

2. Hyman L. Myopic and hyperopic refractive error in adults: an overview. Ophthalmic Epidemiol. 2007;14:192-197.

3. Lin LLK, Shih YF, Hsiao CK, Chen CJ. Prevalence of myopia in Taiwanese schoolchildren: 1983 to 2000. Ann Acad Med Singapore. 2004;33:27-33.

4. Teikari JM, O'Donnell J, Kaprio J, Koskenvuo M. Impact of hereditary in myopia. Hum Hered. 1991;41:151-156. 
5. Hammond CJ, Snieder H, Gilbert CE, Spector TD. Genes and environment in refractive error: the twin eye study. Invest $O p h$ thalmol Vis Sci. 2001;42:1232-1236.

6. Lyhne N, Sjolie AK, Kyvik KO, Green A. The importance of genes and environment for ocular refraction and its determiners: a population based study among 20 - 45 year old twins. Br J Ophthalmol. 2001;85:1470-1476.

7. Dirani M, Chamberlain M, Shekar SN, et al. Heritability of refractive error and ocular biometrics: The genes in myopia (GEM) twin study. Invest Ophthalmol Vis Sci. 2006;47:4756-4761.

8. Zadnik Z, Satariano WA, Mutti DO, Sholtz RI, Adams AJ. The effect of parental history of myopia on children's eye size. J Am Med Assoc. 1994;271:1323-1327.

9. Mutti DO, Hayes JR, Mitchell GL, et al. Refractive error, axial length, and relative peripheral refractive error before and after the onset of myopia. Invest Ophthalmol Vis Sci. 2007;48:2510-2519.

10. Lam DSC, Fan DSP, Lam RF, et al. The effect of parental history of myopia on children's eye size and growth: results of a longitudinal study. Invest Ophthalmol Vis Sci. 2008;49:873-876.

11. Fan DS, Lam DS, Wong TY, et al. The effect of parental history of myopia on eye size of pre-school children: a pilot study. Acta Ophthalmol Scand. 2005;83:492-496.

12. Kurtz D, Hyman L, Gwiazda JE, et al. Role of parental myopia in the progression of myopia and its interaction with treatment in COMET children. Invest Ophthalmol Vis Sci. 2007;48:562-570.

13. Morgan I, Rose K. How genetic is school myopia? Prog Retin Eye Res. 2005;24:1-38

14. Young TL, Metlapally R, Shay AE. Complex trait genetics of refractive error. Arch Ophthalmol. 2007;125:38-48

15. Tang WC, Yap MK, Yip SP. A review of current approaches to identifying human genes involved in myopia. Clin Exp Optom. 2008;91:4-22.

16. Hammond CJ, Andrew T, Mak YT, Spector TD. A susceptibility locus for myopia in the normal population is linked to the PAX6 gene region on chromosome 11: A genomewide scan of dizygotic twins. Am J Hum Genet. 2004;75:294-304.

17. Klein AP, Duggal P, Lee KE, et al. Confirmation of linkage to ocular refraction on chromosome $22 \mathrm{q}$ and identification of a novel linkage region on 1q. Arch Ophthalmol. 2007;125:80-85.

18. Wojciechowski R, Moy C, Ciner E, et al. Genomewide scan in Ashkenazi Jewish families demonstrates evidence of linkage of ocular refraction to a QTL on chromosome 1p36. Hum Genet. 2006;119:389-399.

19. Han W, Yap MK, Wang J, Yip SP. Family based association analysis of hepatocyte growth factor (HGF) gene polymorphisms in high myopia. Invest Ophthalmol Vis Sci. 2006;47:2291-2299.

20. Yanovitch T, Li YJ, Metlapally R, et al. Hepatocyte growth factor and myopia: genetic association analyses in a Caucasian population. Mol Vis. 2009;15:1028-1035

21. Mutti DO, Cooper ME, O'Brien S, et al. Candidate gene and locus analysis of myopia. Mol Vis. 2007;13:1012-1019.

22. Metlapally R, Li Y-J, Tran-Viet K-N, et al. COL1A1, COL2A1 genes and myopia susceptibility: evidence of association and suggestive linkage to the COL2A1 locus. Invest Ophthalmol Vis Sci. 2009; 50(9): 4080 - 4086.

23. Rose KA, Morgan IG, Ip J, et al. Outdoor activity reduces the prevalence of myopia in children. Ophthalmology. 2008;115: $1279-1285$

24. Ip JM, Rose K, Morgan I, Burlutsky G, Mitchell P. Myopia and the urban environment: findings for a sample of 12-year old Australian school children. Invest Ophthalmol Vis Sci. 2008;49:3858-3863.

25. Jones LA, Sinnott LT, Mutti DO, et al. Parental history of myopia, sports and outdoor activities, and future myopia. Invest Ophthalmol Vis Sci. 2007;48:3524-3532

26. Dirani M, Tong L, Gazzard G, et al. Outdoor activity and myopia in Singapore teenage children. Br J Ophthalmol. 2009;93:997-1000.

27. Lu B, Congdon N, Liu X, et al. Associations between near work, outdoor activity, and myopia among adolescent students in rural China: the Xichang Pediatric Refractive Error Study report no. 2. Arch Ophthalmol. 2009;127:769-775.

28. Mutti DO, Zadnik K. Has near work's star fallen? Optom Vis Sci. 2009;86:76-78
29. Hornbeak DM, Young TL. Myopia genetics: a review of current research and emerging trends. Curr Opin Opbthalmol. 2009; 20(5):356-362.

30. Wallman J, Turkel J, Trachtman J. Extreme myopia produced by modest changes in early visual experience. Science. 1978;201: 1249-1251.

31. Sherman SM, Norton TT, Casagrande VA. Myopia in the lid sutured tree shrew. Brain Res. 1977;124:154-157.

32. Wiesel TN, Raviola E. Myopia and eye enlargement after neonatal lid fusion in monkeys. Nature. 1977;266:66-68.

33. Troilo D, Judge SJ. Ocular development and visual deprivation myopia in the common marmoset (Callithrix jacchus). Vision Res. 1993;33:1311-1324.

34. Tejedor $\mathrm{J}$, de la Villa P. Refractive changes induced by form deprivation in the mouse eye. Invest Ophthalmol Vis Sci. 2003; 44:32-36

35. McFadden SA, Howlett MH, Mertz JR. Retinoic acid signals the direction of ocular elongation in the guinea pig eye. Vision Res. 2004; $44: 643-653$

36. McBrien NA, Adams DW. A longitudinal investigation of adultonset and adult-progression of myopia in an occupational group: refractive and biometric findings. Invest Ophthalmol Vis Sci. 1997; 38:321-333.

37. Wildsoet CF. Structural correlates of myopia. In: Rosenfield M, Gilmartin B, eds. Myopia and Nearwork. Oxford, UK: Butterworth-Heinemann; 1998:31-57.

38. Troilo D, Li T, Glasser A, Howland HC. Differences in eye growth and the response to visual deprivation in different strains of chicken. Vision Res. 1995;25:1211-1216.

39. Schmid K, Wildsoet $\mathrm{C}$. Breed- and gender-dependent differences in eye growth and form deprivation responses in chick. J Comp Physiol A. 1996;178:551-561.

40. Shen W, Sivak JG. Eyes of a lower vertebrate are susceptible to the visual environment. Invest Ophthalmol Vis Sci. 2007;48:48294837.

41. Zhu XS, Lin T, Stone RA, Laties AM. Sex differences in chick eye growth and experimental myopia. Exp Eye Res. 1995;61:173-179.

42. Schaeffel F, Howland HC. Properties of the feedback loops controlling eye growth and refractive state in the chicken. Vision Res. 1991;31:717-734

43. Saltarelli D, Wildsoet C, Nickla D, Troilo D. Susceptibility to formdeprivation myopia in chicks is not altered by an early experience of axial myopia. Optom Vis Sci. 2004;81:119-126.

44. Prashar A, Hocking PM, Erichsen JT, et al. Common determinants of body size and eye size in chickens from an advanced intercross line. Exp Eye Res. 2009;89:42-48.

45. Griffiths R, Double MC, Orr K, Dawson RJG. A DNA test to sex most birds. Mol Ecol. 1998;7:1071-1075.

46. Nota Y, Takenaka O. DNA extraction from urine and sex identification of birds. Mol Ecol. 1999;8:1237-1238.

47. Guggenheim JA, Erichsen JT, Hocking PM, Wright NF, Black R. Similar genetic susceptibility to form-deprivation myopia in three strains of chicken. Vision Res. 2002;42:2747-2756.

48. Wallman J, Adams JI. Developmental aspects of experimental myopia in chicks: susceptibility, recovery and relation to emmetropization. Vision Res. 1987;27:1139-1163.

49. Stone RA, Lin T, Desai D, Capehart C. Photoperiod, early post-natal eye growth and visual deprivation. Vision Res. 1995;35:11951202.

50. Shen W, Vijayan M, Sivak JG. Inducing form-deprivation myopia in fish. Invest Ophthalmol Vis Sci. 2005;46:1797-1803.

51. Bishop KM, Wahlsten D. Sex and species differences in mouse and rat forebrain commissures depend on the method of adjusting for brain size. Brain Res. 1999;815:358-366.

52. Matsumura $\mathrm{H}$, Hirai $\mathrm{H}$. Prevalence of myopia and refractive changes in students from 3 to 17 years of age. Surv Ophthalmol. 1999; 44:S109-S115.

53. Saw SM, Chan YH, Wong WL, et al. Prevalence and risk factors for refractive errors in the Singapore Malay Eye Survey. Ophthalmology. 2008;115:1713-1719. 
54. Schwartz M, Haim M, Skarsholm D. X-linked myopia: Bornholm eye disease: linkage to DNA markers on the distal part of Xq. Clin Genet. 1990;38:281-286.

55. Zhang Q, Guo X, Xiao X, et al. Novel locus for X linked recessive high myopia maps to Xq23-q25 but outside MYP1. J Med Genet. 2006; 43:e20.

56. Zhang Q, Xiao X, Li S, et al. Mutations in NYX of individuals with high myopia, but without night blindness. Mol Vis. 2007;13:330 336.

57. Stambolian D, Ciner EB, Reider LC, et al. Genome-wide scan for myopia in the Old Order Amish. Am J Opbthalmol. 2005;5:469476.

58. Nanda I, Schlegelmilch K, Haaf T, Schartl M, Schmid M. Synteny conservation of the $\mathrm{Z}$ chromosome in 14 avian species (11 families) supports a role for $\mathrm{Z}$ dosage in avian sex determination. Cytogenet Genome Res. 2008;122:150-156.

59. Nanda I, Haaf T, Schartl M, Schmid M, Burt DW. Comparative mapping of Z-orthologous genes in vertebrates: implications for the evolution of avian sex chromosomes. Cytogenet Genome Res. 2002;99:178-184.

60. Schmid M, Nanda I, Guttenbach M, et al. First report on chicken genes and chromosomes 2000. Cytogenet Cell Genet. 2000;90: $169-218$.

61. Nanda I, Shan Z, Schartl M, et al. 300 million years of conserved synteny between chicken $\mathrm{Z}$ and human chromosome 9. Nat Genet. 1999;21:258-259.
62. Nanda I, Zend-Ajusch E, Shan Z, et al. Conserved synteny between the chicken $Z$ sex chromosome and human chromosome 9 includes the male regulatory gene DMRT1: a comparative (re)view on avian sex determination. Cytogenet Cell Genet. 2000;89:67-78.

63. Goldschmidt E. On the Etiology of Myopia: An Epidemiological Study. Copenhagen, Denmark: Munksgaard, Bogtrykkeriet Forum; 1968.

64. Lin LL, Shih YF, Tsai CB, et al. Epidemiologic study of ocular refraction among schoolchildren in Taiwan in 1995. Optom Vis Sci. 1999;76:275-281.

65. Wong TY, Foster PJ, Hee J, et al. Prevalence and risk factors for refractive errors in adult Chinese in Singapore. Invest Opbthalmol Vis Sci. 2000;41:2486-2494.

66. Zhao J, Mao J, Luo R, et al. The progression of refractive error in school-age children: Shunyi district, China. Am J Opbthalmol. 2002;134:735-743.

67. He M, Huang W, Zheng Y, Huang L, Ellwein LB. Refractive error and visual impairment in school children in rural southern China. Ophthalmology. 2007;114:374-382.

68. Xu L, Li J, Cui T, et al. Refractive error in urban and rural adult Chinese in Beijing. Opbthalmology. 2005;112:1676-1683.

69. Vitale S, Ellwein L, Cotch MF, Ferris FL 3rd, Sperduto R. Prevalence of refractive error in the United States, 1999-2004. Arch Opbthalmol. 2008;126:1111-1119. 